\title{
Combined XPS and contact angle studies of ethylene vinyl acetate and polyvinyl acetate blends
}

\author{
I.O. Ucar $^{\mathrm{a}}$, M.D. Doganci ${ }^{\mathrm{a}}$, C.E. Cansoy ${ }^{\mathrm{a}}$, H.Y. Erbil ${ }^{\mathrm{a}, *}$, I. Avramova ${ }^{\mathrm{b}}$, S. Suzer $^{\mathrm{b}}$ \\ a Department of Chemical Engineering, Gebze Institute of Technology, 41400 Kocaeli, Turkey \\ ${ }^{\mathrm{b}}$ Department of Chemistry, Bilkent University, 06800 Ankara, Turkey
}

\section{A R T I C L E I N F O}

\section{Article history:}

Received 1 January 2011

Received in revised form 21 March 2011

Accepted 13 June 2011

Available online 21 June 2011

\section{Keywords:}

Ethylene vinyl acetate copolymers

Polymer blending

Surface free energy

XPS

Contact angle

Polyolefin

\begin{abstract}
A B S T R A C T
In this study, we prepared thin films by blending ethylene vinyl acetate copolymers (EVA) containing 12-33 (wt.\%) vinyl acetate (VA) with polyvinyl acetate (PVAc) and high density polyethylene homopolymers. Large area micropatterns having controlled protrusion sizes were obtained by phase-separation especially for the PVAc/EVA-33 blends using dip coating. These surfaces were characterized by XPS and contact angle measurements. A reasonably linear relation was found between the VA content on the surface (wt.\%) obtained from XPS analysis and the VA content in bulk especially for PVAc/EVA-33 blend surfaces. PE segments were more enriched on the surface than that of the bulk for pure EVA copolymer surfaces similar to previous reports and VA enrichment was found on the EVA/HDPE blend surfaces due to high molecular weight of HDPE. Water $\theta_{e}$ decreased with the increase in the VA content on the blend surface due to the polarity of VA. A good agreement was obtained between $\gamma_{s}^{-}$and atomic oxygen surface concentration with the increase of VA content. The applicability of Cassie-Baxter equation was tested and found that it gave consistent results with the experimental water contact angles for the case where VA content was lower than $55 \mathrm{wt} . \%$ in the bulk composition.
\end{abstract}

() 2011 Elsevier B.V. All rights reserved.

\section{Introduction}

Polymer blending is a cheap surface modification method to obtain desired surface properties of thin polymer coatings rather than comparatively expensive methods such as plasma treatment, surface grafting, film deposition under vacuum etc. [1]. When polymers are blended, the preferential enrichment of some functional groups on the surface affects the final properties and applications of these films. Phase-separated rough or comparatively flat surfaces can be obtained by choosing convenient polymer-solvent blending systems such as homopolymer-homopolymer, homopolymer-statistical copolymer, homopolymer-block copolymer, statistical copolymer-statistical copolymer [1-5]. Surface free energy, miscibility, viscosity at the process temperature, and solubility of each polymer in the chosen solvent of the blend components are the most important factors which affect the blending process and the resultant films [1-5]. The molecular weight of these polymers, film thickness and the solvent evaporation rate are the other important parameters $[1,4]$. This paper is about preparation and surface characterization of PVAc homopolymer/EVA-33 copolymer blends having different VA contents in bulk solution. We coated glass slides with the polymer blends by applying dip

\footnotetext{
* Corresponding author. Tel.: +90 262 6052114; fax: +90 2626052105.

E-mail address: yerbil@gyte.edu.tr (H.Y. Erbil).
}

coating into polymer blend solutions and determined both the wettability and the surface enrichment of PE and VA contents by phase-segregation on these blend surfaces after drying in relation to the bulk VA content of the blend solution.

In a phase-segregation process, the surface free energy differences of the involved polymers are the driving force $[2,3,5]$. However, some researchers rejected this view and attributed the surface segregation with the conformational entropy differences between the surface and bulk [6,7]. According to this group conformational entropy in the bulk is higher than in the surface and when the number average molecular weight $\left(M_{n}\right)$ decreases, the conformational entropy of a chain at the film surface also decreases. Consequently, macromolecule having lower molecular weight will be at the blend surface in order to minimize the conformational entropy. This view can be disputed so that when a volatile solvent is used in casting of the polymer blend films, the solvent evaporates rapidly from the substrate and thus the system cannot be considered as an equilibrium process. For such non-equilibrium processes, polymer surface tensions and polymer-solvent interactions play much more important roles. This situation was explained by spreading coefficient concept for the polymer blends $[1,8]$. Li et al. [8] studied the formation of polystyrene and polymethylmethacrylate blend films and low surface tension polystyrene was found to locate over the polymethylmethacrylate layer and spreading coefficient calculations supported this result. 
Polyethylene vinyl acetate copolymer (EVA), which is a widely used thermoplastic resin, has been considered to be a good candidate to be used as a biomedical material due to its good physical properties, ease of handling and processing, and moderate biocompatibility [9]. EVA was recently used to test the removal of the sporelings of the green alga Ulva for marine fouling applications [10]. Ethylene vinyl acetate copolymers are produced by random copolymerization of ethylene and vinyl acetate monomers, which are mainly recognized for their flexibility, toughness (even at low temperatures) and adhesion characteristics [11]. Properties of EVA copolymers change mostly due to the variation of the VA content. When polar VA content is increased, the relative quantity of amorphous phase increases and the degree of crystallinity that comes from polyethylene decreases. Increasing the VA content changes the final copolymer from modified polyethylene to rubber-like products and some of the properties such as flexibility, elongation, adhesion and solubility in organic solvents improve [11,12]. It is possible to modify EVA copolymer surfaces by blending with polyethylene (PE) and polyvinyl acetate (PVAc) homopolymers.

Contact angle measurements and surface free energy calculations are useful techniques not only for homopolymer and copolymer surfaces, but also for polymer blend surfaces to characterize film surfaces at the top layer. Surface free energy analysis of LDPE/EVA blends were previously studied by Chattopadhyay et al. [3]. Contact angle measurements and surface free energy calculations for LDPE/EVA blends were also evaluated by Ali [5] who concluded that the modification of the surface polarity occurred when the VA content of EVA copolymer increased. As a result of this increase, contact angles for water and reference liquids decreased and calculated surface free energy values raised [5]. Matsunaga and Tamai [13] and later Erbil [14] determined surface free energy values of EVA copolymers by applying contact angle method. The same method was also applied to polyethylene homopolymer by Dann [15] and Park et al. [16].

van Oss et al. [17] developed a successful approach to estimate the surface free energy of polymers. According to this theory, Lifshitz-van der Waals interactions (indicated by superscript LW) include dispersion, polar-polar, and induction interactions, and acid base interactions (indicated by superscript $A B$ ) include hydrogen-bonding interactions, in other words electron donor-acceptor interactions. Total surface free energy is the sum of these Lifshitz-van der Waals and acid-base interactions [17]. Surface free energy determination of EVA copolymers by applying van Oss-Good-Chaudhury method was studied by Grundke et al. [18]. Similarly, Michalski et al. [2] applied van Oss-Good-Chaudhury method to determine the surface free energy of EVA, PVC and their blends.

X-ray photoelectron spectroscopy (XPS) was applied to determine the surface compositions of the EVA copolymers and its blends which have varying VA contents [19-21]. Chihani et al. [19] used XPS characterization of the EVA surfaces obtained by the injection molding method and found that surface concentration of VA groups was higher than that of the bulk when perfluorinated ethylene propylene (FEP) was used as the mould. Galuska [20] studied EVA copolymer and EVA/LDPE blend surfaces by using XPS and obtained a linear relation between surface and bulk VA content according to oxygen concentration. Surface properties of EVA copolymers were modified by treatment with low pressure RF plasmas [22], UV radiation [23] and the change of its adhesion properties were determined by contact angle measurements and XPS.

In a previous study, we investigated the surface chemical structure and wetting properties of both flat and rough EVA copolymer films by varying the concentration and temperature of the dip coating solution [24]. A solution concentration of $40 \mathrm{mg} / \mathrm{ml}$ was used for the flat coatings and up to $100 \mathrm{mg} / \mathrm{ml}$ for the rough coatings and the temperatures changed from room temperature to $125^{\circ} \mathrm{C}$.
XPS analysis at $0^{\circ}$ and $60^{\circ}$ take-off angles (approximately $10 \mathrm{~nm}$ and $5 \mathrm{~nm}$ depths, respectively) was applied and contact angle measurements were carried out by increasing the VA content of the bulk EVA copolymer. XPS results show that hydrophobic PE component was enriched on EVA surfaces around $5 \mathrm{~nm}$ depth for all the samples, whereas hydrophilic VA component was enriched on the surfaces when VA $<18 \%$ for only around $10 \mathrm{~nm}$ depth. Hydrophobic PE component was found to enrich in the near-surface region for all flat and rough EVA samples for a depth of around $5 \mathrm{~nm}$. The difference between the XPS results of the flat and rough surfaces was not significant for EVA samples except EVA-33 surface where the atomic oxygen content decreased $15 \%$ for $10 \mathrm{~nm}$ and $20 \%$ for $5 \mathrm{~nm}$ depth due to its very low molecular weight [24].

In the present study, we applied dip coating of glass slides in polymer blend solutions of EVA-33 copolymer with PVAC homopolymer for the first time and determined both the wettability of dried blend surfaces and the surface enrichment of PE and VA contents by phase-segregation in relation to the VA content of the blend solution in bulk. In addition, we also blended EVA copolymers (EVA-12, EVA-18, EVA-28 and EVA-33) with HDPE homopolymer for comparison. Contact angle, surface free energy analysis and XPS measurements were done in order to investigate the wettability properties and surface compositions of these blend surfaces. The correlation of surface free energy with the XPS results was discussed and the applicability of the Cassie-Baxter equation [25], which was derived for the chemically heterogeneous surfaces; was also investigated for the blend surfaces.

\section{Experimental}

\subsection{Materials}

Polyvinyl acetate and high density polyethylene (HDPE) homopolymers and ethylene-vinyl acetate copolymers with varying VA contents (EVA-12, EVA-18, EVA-28-05, EVA-28-40, EVA28-150, EVA-33 and EVA-40) were used for the preparation of blend surfaces. The names of EVA copolymers are self-descriptive, for example that EVA-28-40 has a VA content of $28 \mathrm{wt} . \%$, with a melt flow index of 40 . The names of manufacturers, vinyl acetate (VA) contents and also experimentally determined melt flow index values (MFI) of the polymers are given in Table 1 . All homopolymers and copolymers were used as received. Standard glass slides (76 mm $\times 26 \mathrm{~mm}$, ISOLAB, Turkey) were used in the experiments. A two-component polyepoxide layer (404 Chemicals, Turkey) was applied as the primer coating on the glass slides for the films to be used for contact angle measurements. MERCK spectroscopic grade water, methylene iodide, ethylene glycol and formamide liquids were used in static and dynamic contact angle measurements.

\subsection{Preparation of polymeric coatings}

Glass slides were used as substrates and cleaned in chromic acid, rinsed with distilled water and dried in a vacuum oven at $100^{\circ} \mathrm{C}$. A polyepoxide layer ( 404 adhesive) was deposited on glass slides by applying dip coating from its chloroform solution as the primer coating to compensate for the weak adherence of polymers onto glass slides. Polyepoxide primer was only applied for samples, which were used in the contact angle measurements. Thin films from blends of EVA copolymers containing 12-33 wt.\% VA contents with PVAc and HDPE homopolymers were prepared from their xylene (mixture of o-, m-, p-isomers, m-predominating) solutions at high temperatures by dip coating technique. The concentration of all the polymer solutions was $20 \mathrm{mg} / \mathrm{ml}$. Clean glass slides were dipped into the polymer solutions by using a precise home-made mechanical dipper at $130^{\circ} \mathrm{C}$ and withdrawn from the polymer solu- 
Table 1

Characteristics of polymers.

\begin{tabular}{|c|c|c|c|c|c|}
\hline Polymer & $\begin{array}{l}\text { VA content in } \\
\text { bulk (wt.\%) }\end{array}$ & $\begin{array}{l}\mathrm{MFI}^{\mathrm{a}}(\mathrm{g} / 10 \mathrm{~min}) \mathrm{ASTM} \\
\mathrm{D} 1238\left(2.16 \mathrm{~kg}, 190^{\circ} \mathrm{C}\right)\end{array}$ & $\begin{array}{l}\text { MFI }(g / 10 \mathrm{~min}) \\
\text { experimental }(2.16 \mathrm{~kg} \text {, } \\
\left.190^{\circ} \mathrm{C}\right)\end{array}$ & Manufacturer & Commercial name \\
\hline HDPE & 0 & $\mathrm{~N} / \mathrm{A}$ & 0.16 & Lyondell Basell & HOSTALEN GM 8255 \\
\hline EVA-12 & 12 & 2.5 & 2.2 & DuPont Inc. & ELVAX 660 \\
\hline EVA-18 & 18 & 1.8 & 1.8 & Asia Polymer Corp. & EV101 \\
\hline EVA-28-05 & 28 & $5-8$ & 5 & Arkema Ltd. & EVATANE \\
\hline EVA-28-40 & 28 & $35-45$ & 33 & Arkema Ltd. & EVATANE \\
\hline EVA-28-150 & 28 & $135-175$ & 124 & Arkema Ltd. & EVATANE \\
\hline EVA-33 & 33 & $350-450$ & 375 & Arkema Ltd. & EVATANE \\
\hline EVA- $40^{\mathrm{b}}$ & 40 & 57 & $\mathrm{~N} / \mathrm{A}$ & Aldrich & - \\
\hline PVAc $^{\mathrm{b}}$ & 100 & $\mathrm{~N} / \mathrm{A}$ & 105 & Aldrich & - \\
\hline
\end{tabular}

a Quoted from suppliers' catalogues.

b Molecular weights of EVA-40 and PVAc are $42.000 \mathrm{~g} / \mathrm{mol}$ and $100.000 \mathrm{~g} / \mathrm{mol}$ respectively [32].

tions at specific rate of $320 \mathrm{~mm} / \mathrm{min}$. High temperatures and low deposition rates were used to achieve comparatively flat coatings. Coated glass slides were dried in a vacuum oven overnight at $25^{\circ} \mathrm{C}$ and kept in a desiccator.

\subsection{Static and dynamic contact angle measurements}

KSV-CAM 200-Finland contact angle meter was used to measure the static contact angles of the liquids under air. Equilibrium $\left(\theta_{e}\right)$ contact angles of water, methylene iodide, ethylene glycol and formamide were measured by using $5 \mu \mathrm{l}$ droplet volumes to neglect the gravity flattening effect. The needle was removed from the droplet during the $\theta_{e}$ measurement however it was kept within the liquid droplets during the advancing $\left(\theta_{a}\right)$ and receding $\left(\theta_{r}\right)$ contact angle measurements. First a droplet of $3 \mu \mathrm{l}$ volume was formed and its volume was increased to $8 \mu$ l during the $\theta_{a}$ measurement. An initial drop volume of $8 \mu \mathrm{l}$ was decreased to $2 \mu \mathrm{l}$ while measuring the $\theta_{r}$. Contact angle measurements were taken over 3 different areas for each polymer sample. Average and standard deviation of $\theta$ values were calculated as less than \pm 2 . Water dynamic contact angle measurements were carried out using a KSV Sigma 700 Dynamic Tensiometer apparatus at room temperature, using the polymer coated glass slides as Wilhelmy plates dipping in pure water.

\subsection{Optical microscopy}

Surface topography of all the coated samples were investigated by using a NIKON ECLIPSE LV 100 Optical Microscope with $\times 500$ magnification.

\subsection{X-ray photoelectron spectroscopy}

XPS investigations were carried out by means of a Kratos 800 spectrometer with $\mathrm{Mg} \mathrm{K} \alpha$ (unmonochromatized) source at $1253.6 \mathrm{eV}$ with a total instrumental resolution of $\sim 1 \mathrm{eV}$, under a base pressure of $10^{-8}$ mbar. The $\mathrm{C} 1 \mathrm{~s}$ and $01 \mathrm{~s}$ photoelectron lines were recorded and calibrated to the $\mathrm{C} 1 \mathrm{~s}$ line at $285.0 \mathrm{eV}$. XPSPEAK 4.0 fitting program was used for deconvolution of the photoelectron peaks. The atomic sensitivity factor has been evaluated as given in [26]. All data were recorded at $90^{\circ}$ take-off angle, corresponding to maximum sampling depth of approximately $8 \mathrm{~nm}$.

\section{Results and discussions}

\subsection{Optical microscopy images}

Optical microscope images of PVAc/EVA-33 blends with varying VA contents at $\times 500$ magnification are given in Fig. 1. Large area patterns having specific protrusion sizes were obtained as seen in this figure, where the size of protrusions was decreased with the increase of VA content in the bulk EVA copolymer. It can be speculated that the protrusions correspond to PE regions since their total area on the surface decreases with the increase of VA content.

\section{2. $X P S$ results}

$\mathrm{X}$-ray photoelectron lines of $\mathrm{C} 1 \mathrm{~s}$ and $\mathrm{O} 1 \mathrm{~s}$ have been recorded for the polymers listed in Table 2, and were deconvoluted for better evaluation of surface $(\mathrm{O} / \mathrm{C})$ ratio. The $\mathrm{C} 1 \mathrm{~s}$ peaks are complex and can be curve-fitted to three peaks assigned to hydrocarbon $(\mathrm{C}-\mathrm{H})$, etheric $(\mathrm{C}-\mathrm{O})$ and carbonyl $(\mathrm{C}=\mathrm{O})$ groups on the surface at around $285.0 \mathrm{eV}, 286.5 \mathrm{eV}$ and $289.1 \mathrm{eV}$ respectively. The $01 \mathrm{~s}$ peaks are curve-fitted to two peaks, which are associated with $(\mathrm{C}-\mathrm{O})$ and $(\mathrm{C}=0)$ groups. $\mathrm{X}$-ray photoelectron line of $\mathrm{C} 1 \mathrm{~s}$ and $01 \mathrm{~s}$ peaks are shown in Fig. 2a and b for the PVAc homopolymer surface as an indicative figure. The main elements on the surface of pure PVAc are oxygen and carbon. The functional composition of pure PVAc film can be determined by curve fitting of $\mathrm{C} 1 \mathrm{~s}$ peak. Three different carbon components were considered: hydrocarbon $(C-\mathrm{H} / C-\mathrm{C})$ at $285.0 \mathrm{eV}$; alcohol or ether $(\mathrm{C}-\mathrm{OH} / \mathrm{C}-\mathrm{O}-\mathrm{C})$ at $286.4 \mathrm{eV}$ and ester $(\mathrm{O}-\mathrm{C}=\mathrm{O})$ at $288.8 \mathrm{eV}$. The $\mathrm{O} 1 \mathrm{~s}$ peak of pure PVAc film consisted of two oxygen functionalities: ester $(\mathrm{C}-\mathrm{O}-\mathrm{C}=\mathrm{O})$ at $534.6 \mathrm{eV}$ and carbonyl $(\mathrm{O}-\mathrm{C}=\mathrm{O})$ at $533.2 \mathrm{eV}$ [27]. Blend ratios, bulk and surface VA contents of EVA copolymers are given in Table 2. Oxygen to carbon ratios $(\mathrm{O} / \mathrm{C})$ and atomic oxygen concentrations are also given in this table. The surface oxygen atomic concentrations measured at $90^{\circ}$ take-off angle for a depth of $8 \mathrm{~nm}$, were $1-19 \%$ lower than the theoretical values calculated from the bulk copolymer composition for all the pure EVA copolymers. This is in agreement with the previous reports indicating that PE segments are more enriched at the surface than VA segments for EVA copolymers by dip or spin coating [20,24].

The change of VA content on the PVAc/EVA-33 blend surface versus the VA content in the bulk is given in Table 2 and Fig. $3 a$. As seen in this figure the change of VA content on the surface for a depth of $8 \mathrm{~nm}$ (at $90^{\circ}$ take-off angle) was not significant when all the data points were considered indicating that neither PE nor VA enrichment occurred. We also determined that similar to the previous findings [20,24], PE segments were more enriched at the surface for a depth of $8 \mathrm{~nm}$ for pure EVA copolymers as shown in Fig. 3b where the surface atomic oxygen concentrations were $1-19 \%$ lower than the theoretical values calculated from the bulk copolymer. However, an opposite behavior was seen for all of the EVA/HDPE blends as seen from the data points of (50/50) compositions of EVA-12, EVA-18 EVA-28, EVA-33 with HDPE as given in Fig. 3b and atomic $O$ concentrations measured at $90^{\circ}$ take-off angle were found to be 37-62\% larger than the theoretical values for EVA/HDPE blend surfaces indicating VA enrichment at these blend surfaces. Natu- 
Table 2

Theoretical and experimental results of XPS.

\begin{tabular}{|c|c|c|c|c|c|c|}
\hline Polymer & $\begin{array}{l}\text { Theoretical } \\
\text { VA\% bulk }\end{array}$ & $\mathrm{O} / \mathrm{C}$ & $\%$ mol atomic 0 & $\begin{array}{l}90^{\circ} \text { Take-off angle } \\
\text { VA\% surf. }\end{array}$ & $\mathrm{O} / \mathrm{C}$ & $\%$ mol atomic $\mathrm{O}$ \\
\hline HDPE & 0 & 0.000 & 0.00 & 1.22 & 0.004 & 0.40 \\
\hline EVA-12/HDPE (50/50) & 6 & 0.020 & 1.96 & 8.93 & 0.030 & 2.91 \\
\hline EVA-18/HDPE (50/50) & 9 & 0.030 & 2.94 & 14.58 & 0.050 & 4.76 \\
\hline EVA-12 & 12 & 0.041 & 3.92 & 11.78 & 0.040 & 3.85 \\
\hline EVA-28/HDPE (50/50) & 14 & 0.048 & 4.58 & 22.63 & 0.080 & 7.41 \\
\hline EVA-33/HDPE (50/50) & 16.5 & 0.057 & 5.40 & 22.63 & 0.080 & 7.41 \\
\hline EVA-18 & 18 & 0.063 & 5.89 & 17.32 & 0.060 & 5.66 \\
\hline EVA-28-05 & 28 & 0.101 & 9.19 & 22.63 & 0.080 & 7.41 \\
\hline EVA-28-40 & 28 & 0.101 & 9.19 & 22.63 & 0.080 & 7.41 \\
\hline EVA-28-150 & 28 & 0.101 & 9.19 & 27.74 & 0.100 & 9.09 \\
\hline EVA-33 & 33 & 0.122 & 10.84 & 27.74 & 0.100 & 9.09 \\
\hline EVA-40 & 40 & 0.152 & 13.16 & 32.66 & 0.120 & 10.71 \\
\hline PVAc/EVA-33 (20/80) & 46.4 & 0.180 & 15.29 & 48.49 & 0.190 & 15.97 \\
\hline PVAc/EVA-33 (30/70) & 53.1 & 0.212 & 17.52 & 52.65 & 0.210 & 17.36 \\
\hline PVAc/EVA-33 (50/50) & 66.5 & 0.282 & 22.01 & 69.73 & 0.300 & 23.08 \\
\hline PVAc/EVA-33 (65/35) & 76.6 & 0.340 & 25.39 & 81.38 & 0.370 & 27.01 \\
\hline PVAc/EVA-33 (80/20) & 86.6 & 0.404 & 28.78 & 82.94 & 0.380 & 27.54 \\
\hline PVAc/EVA-33 (85/15) & 90 & 0.427 & 29.92 & 84.48 & 0.390 & 28.06 \\
\hline PVAC & 100 & 0.500 & 33.33 & 94.64 & 0.460 & 31.51 \\
\hline
\end{tabular}

(a)

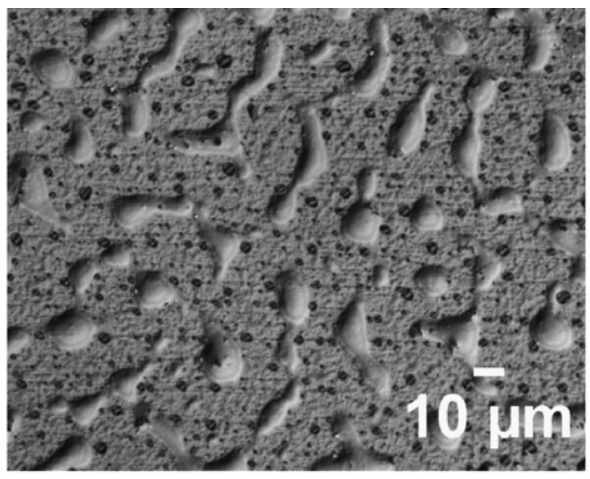

(c)

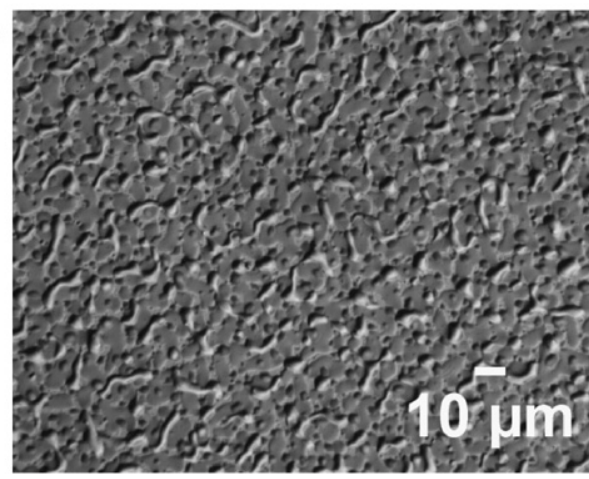

(e)

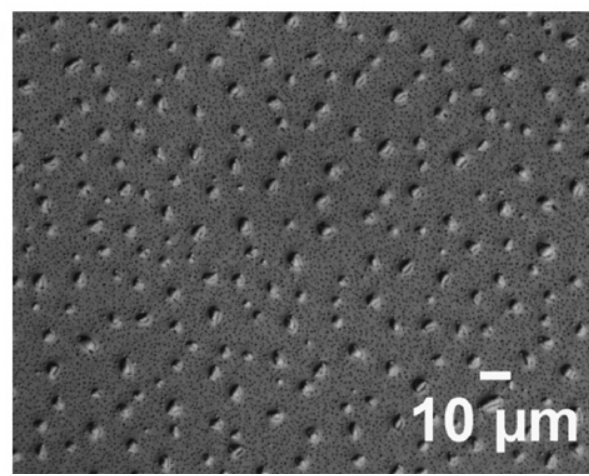

(b)

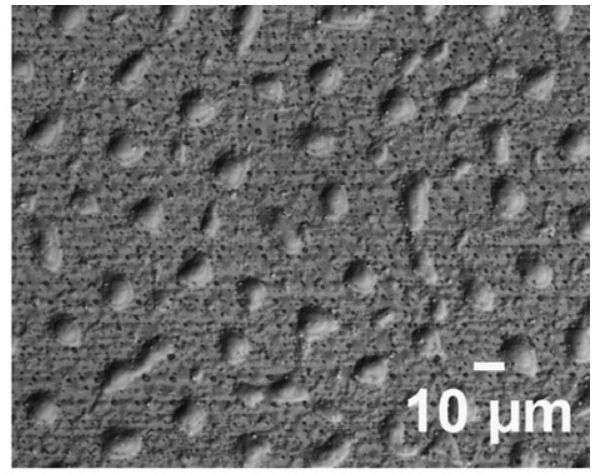

(d)

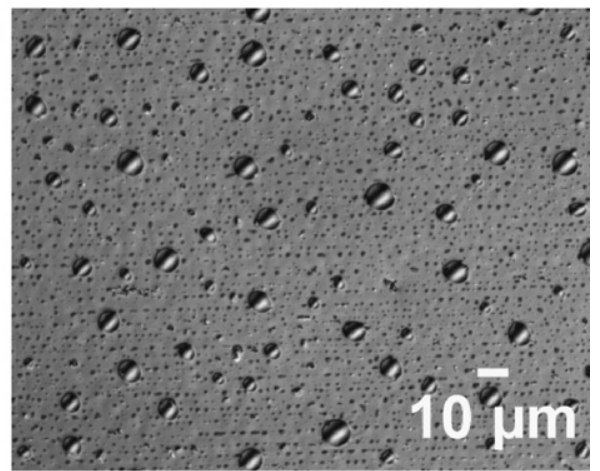

(f)

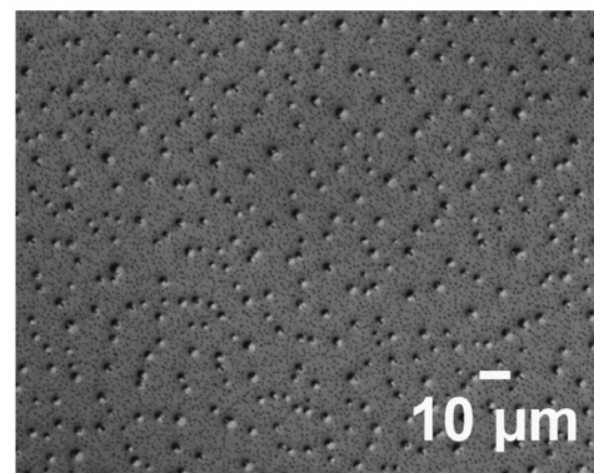

Fig. 1. Optical microscope images of PVAc/EVA-33 blends at X500 magnification (a) 46.4, (b) 53.1, (c) 66.5, (d) 76.6, (e) 86.6, (f) 90 wt.\% VA content in bulk. 
(a)

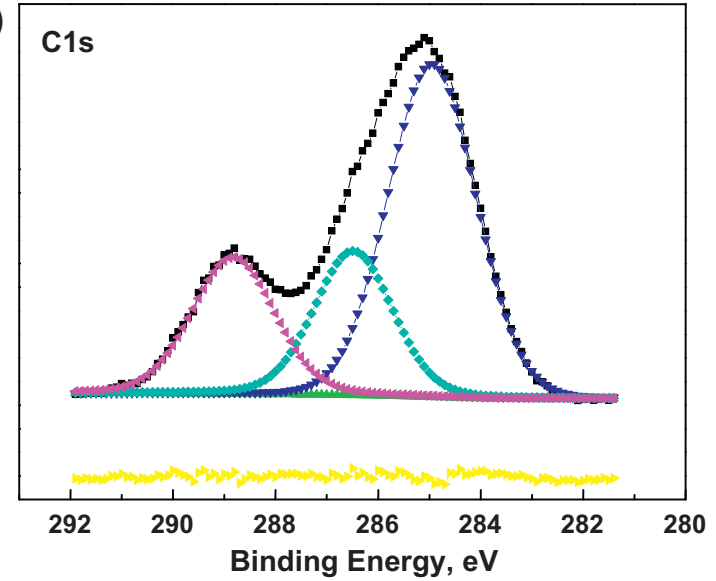

(b)

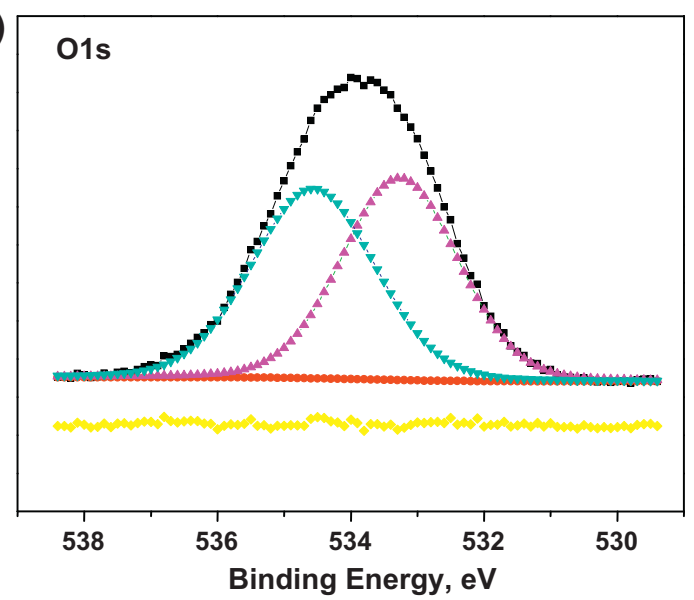

Fig. 2. X-ray photoelectron lines of (a)C1s and (b) O1s peaks for PVAc homopolymer.

rally, PE enrichment is expected for all EVA/HDPE blend surfaces when compared with their bulk composition because PE component having the lower surface free energy should migrate to the solid-air interface in a blending process in order to minimize the interfacial tension in most of the cases.

Thus, the enrichment of VA content on the EVA/HDPE blend surface was an exception and needs an explanation: Since a phaseseparation occurs during the formation of EVA-polyolefin blends, it creates regions where VA or PE were more concentrated on the blend surface depending on the VA content [28], density and molecular weight of the used polymers. The VA enrichment on the EVA/HDPE blend surface may be attributed to the lower MFI value of HDPE than all of the EVA copolymers, which allows the EVA content having lower $M_{w}$ than HDPE to go up to the near surface. The maximum VA enrichment was seen for the (50/50) EVA-28/HDPE blend composition. The increase in the VA content of EVA copolymer in bulk also increases the VA content on the EVA/HDPE blend surface (40-67\% as O/C ratio), except for EVA-33/HDPE blend because of the low $M_{w}$ of EVA-33 copolymer having a very high MFI value as given in Table 1.

Nevertheless, the surface VA compositions obtained from the XPS measurements generally fitted with the corresponding bulk compositions within a thin band as seen in Fig. 3a and b, although minor deviations occurred. Thus, PVAc/EVA-33 blend surfaces can be used as practical test surfaces where the VA contents of the blends on the surface can be calculated by adding the VA fraction of the PVAc homopolymer and EVA-33 copolymer in the bulk composition.
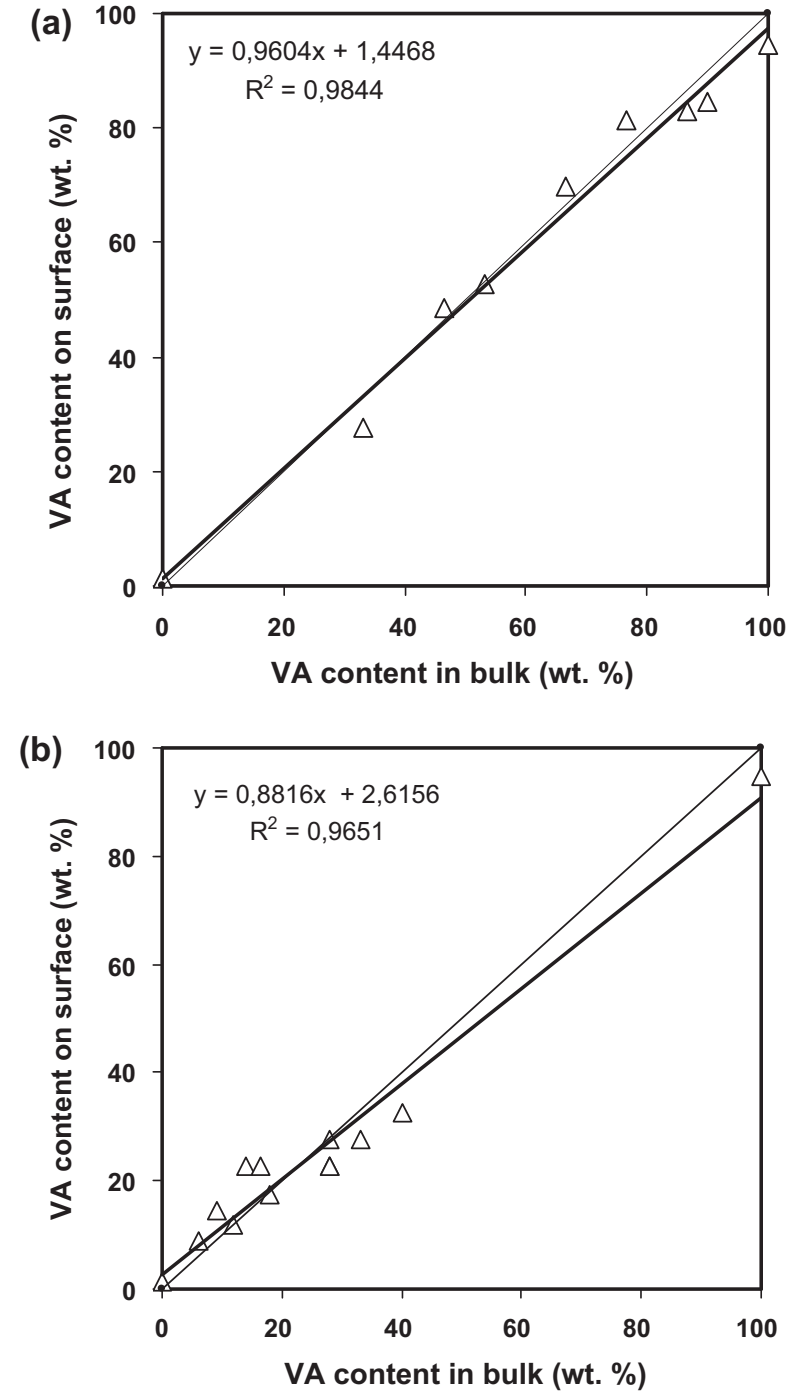

Fig. 3. Dependence of VA content on surface (wt.\%) versus the VA content in bulk for: (a) PVAc/EVA-33 blends, (b) EVA/HDPE blends and EVA copolymers.

\subsection{Contact angle and surface free energy results}

Static advancing, $\theta_{a}$, equilibrium, $\theta_{e}$, and receding contact angle, $\theta_{r}$ measurement results obtained by KSV-CAM 200-Finland contact angle meter and dynamic $\theta_{a}, \theta_{r}$ results of water drops obtained by KSV Sigma 700 Dynamic Tensiometer on all sample surfaces are given in Table 3. Contact angle hysteresis $(\Delta \theta)$, which is the difference between advancing and receding water contact angles, ( $\Delta \theta=\theta_{a}-\theta_{r}$ ), indicates either the chemical heterogeneity for flat surfaces or surface roughness of chemically homogeneous surfaces [4]. Static and dynamic $\Delta \theta$ results of all samples are also given in Table 3. Static water $\theta_{e}$ results of the polymers decreased from $102^{\circ}$ to $60^{\circ}$ with the increase of polar hydrophilic VA content. The same decrease of $\theta_{a}$ and $\theta_{r}$ results with the increase of VA was also seen in Table 3. Static water $\theta_{e}$ results with the change in VA content in bulk (wt.\%) for all of the samples and also the literature data are given in Fig. 4a. The increase of polar VA content on polymer surfaces resulted in a decrease of the water equilibrium contact angles in agreement with the previous reports $[2,14,29,30]$. We plotted both the static and dynamic advancing contact angles with the change in VA content in bulk (wt.\%) for all of the samples in Fig. 4b for comparison. As seen in this figure, a good agreement exists between static and dynamic advancing contact angle results for the samples con- 
Table 3

Static and dynamic water contact angle results of homopolymers and polymer blends.

\begin{tabular}{lrrrrrrr}
\hline & \multicolumn{3}{c}{ Static } & \multicolumn{5}{c}{ Dynamic } \\
Polymer & $\theta_{a}$ & $\theta_{e}$ & $\theta_{r}$ & $\Delta \theta$ & $\theta_{a}$ & $\theta_{r}$ & $\Delta \theta$ \\
\hline HDPE & 109 & 102 & 90 & 19 & 107 & 88 & 19 \\
EVA-12/HDPE (50/50) & 99 & 94 & 76 & 23 & 98 & 78 & 20 \\
EVA-18/HDPE (50/50) & 93 & 87 & 80 & 13 & 93 & 77 & 16 \\
EVA-12 & 93 & 84 & 79 & 14 & 100 & 80 & 20 \\
EVA-28/HDPE (50/50) & 98 & 90 & 77 & 21 & 96 & 72 & 24 \\
EVA-33/HDPE (50/50) & 98 & 87 & 66 & 32 & 96 & 63 & 33 \\
EVA-18 & 92 & 82 & 75 & 17 & 93 & 70 & 23 \\
EVA-28-05 & 88 & 79 & 67 & 21 & 93 & 67 & 26 \\
EVA-28-40 & 92 & 81 & 63 & 29 & 92 & 66 & 26 \\
EVA-28-150 & 93 & 80 & 64 & 29 & 92 & 62 & 30 \\
EVA-33 & 93 & 78 & 48 & 45 & 94 & 48 & 46 \\
EVA-40 & 94 & 77 & 47 & 47 & 96 & 46 & 50 \\
PVAc/EVA-33 (20/80) & 76 & 76 & 50 & 26 & 82 & 46 & 36 \\
PVAc/EVA-33 (30/70) & 75 & 73 & 53 & 22 & 84 & 44 & 40 \\
PVAc/EVA-33 (50/50) & 72 & 62 & 51 & 21 & 83 & 47 & 36 \\
PVAc/EVA-33 (65/35) & 71 & 61 & 50 & 21 & 79 & 40 & 39 \\
PVAc/EVA-33 (80/20) & 72 & 61 & 52 & 20 & 80 & 40 & 40 \\
PVAc/EVA-33(85/15) & 71 & 61 & 53 & 18 & 80 & 38 & 42 \\
PVAc & 80 & 60 & 34 & 46 & 78 & 34 & 44 \\
\hline
\end{tabular}

taining less than $40 \mathrm{wt} . \%$ VA whereas the dynamic $\theta_{a}$ angle results were around $10^{\circ}$ higher than the static ones after $40 \mathrm{wt} . \%$ VA content in bulk, for the PVAc/EVA-33 blend surfaces. This shows that the dynamic contact angle measurement is more sensitive to the surface roughness and chemical heterogeneity than the static contact angle method. On the other hand, lower static $\Delta \theta$ values were
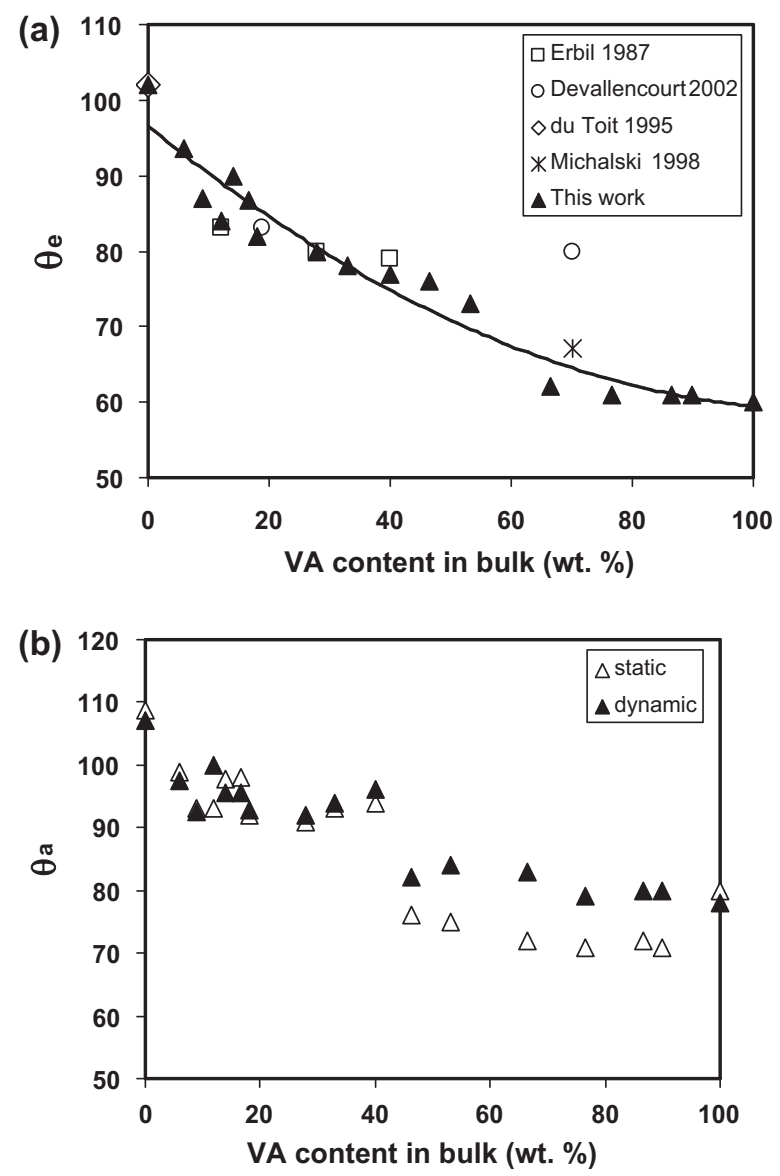

Fig. 4. Dependence of (a) water equilibrium static contact angle (experimental and literature data), (b) water static and dynamic advancing contact angle with the change in VA content in bulk (wt.\%) for all of the polymers.
Table 4

Equilibrium contact angle results of test liquids on polymers.

\begin{tabular}{llll}
\hline Polymer & $\theta_{\text {Mel }_{2}}$ & $\theta_{\text {Formamide }}$ & $\theta_{E G}$ \\
\hline HDPE & 53 & 85 & 72 \\
EVA-12/HDPE (50/50) & 47 & 74 & 69 \\
EVA-18/HDPE (50/50) & 46 & 70 & 67 \\
EVA-12 & 49 & 77 & 71 \\
EVA-28/HDPE (50/50) & 47 & 81 & 71 \\
EVA-33/HDPE (50/50) & 42 & 70 & 70 \\
EVA-18 & 46 & 74 & 70 \\
EVA-28-05 & 45 & 72 & 68 \\
EVA-28-40 & 43 & 77 & 69 \\
EVA-28-150 & 49 & 81 & 72 \\
EVA-33 & 43 & 73 & 74 \\
EVA-40 & 42 & 83 & 73 \\
PVAc/EVA-33 (20/80) & 47 & 65 & 58 \\
PVAc/EVA-33 (30/70) & 49 & 70 & 61 \\
PVAc/EVA-33 (50/50) & 41 & 68 & 65 \\
PVAc/EVA-33 (65/35) & 45 & 53 & 53 \\
PVAc/EVA-33 (80/20) & 45 & 66 & 53 \\
PVAc/EVA-33 (85/15) & 45 & 62 & 52 \\
PVAc & 41 & 43 & 54 \\
\hline
\end{tabular}

obtained for PVAc/EVA-33 blend surfaces than that of the pure PVAc and EVA-33 surfaces, although there is not any direct relationship between the contact angle hysteresis and the VA content. We may attribute the decrease in $\Delta \theta$ to the decrease of surface roughness during blending PVAc and EVA-33. It was found that our results of pure EVA were close to the reported $\theta_{a}$ values given in $[19,22,23]$. Surfaces having higher VA contents were also studied in the literature by using EVA copolymers with high VA content [29] or EVA blends [2]. Michalski et al. [2] reported water $\theta_{e}$ of EVA-70 (70 wt.\% VA content) copolymer as $67.1^{\circ}$, which is close to our value of $62^{\circ}$ for the PVAc/EVA-33 (50/50) blend surface which has $66.5 \mathrm{wt} . \% \mathrm{VA}$ content in bulk.

Surface free energy of a solid can be determined by $\theta_{e}$ measurements of different test liquid drops on the solid surface [4,17]. We applied van Oss [17] method for the surface free energy calculations.

$\gamma_{\mathrm{LV}}(1+\cos \theta)=2\left(\sqrt{\gamma_{S}^{\mathrm{LW}} \gamma_{L}^{\mathrm{LW}}}+\sqrt{\gamma_{S}^{+} \gamma_{L}^{-}}+\sqrt{\gamma_{S}^{-} \gamma_{L}^{+}}\right)$

where subscript $S$ is solid, $L$ is liquid, $V$ is vapor, superscript LW denotes the "Lifshitz-van der Waals interactions" and AB denotes the "acid-base interactions", and $\gamma_{i}^{+}$is the Lewis acid, and $\gamma_{i}^{-}$is the Lewis base parameter of surface free energy, $\left(\gamma_{i}^{\mathrm{AB}}=2 \sqrt{\gamma_{i}^{+} \gamma_{i}^{-}}\right)$. Both the solid surface and liquid drop consists of two surface free energy component terms, one is $\gamma^{\mathrm{LW}}$ comprising "dispersion", "dipolar", and "induction" interactions and the other term is $\gamma^{\mathrm{AB}}$ comprising all the electron donor-acceptor interactions, such as hydrogen-bonding. Their sum gives the total surface free energy $\left(\gamma_{i}^{\mathrm{Tot}}=\gamma_{i}^{\mathrm{LW}}+\gamma_{i}^{\mathrm{AB}}\right)$. We need a set of values of $\gamma_{L}^{\mathrm{LW}}, \gamma_{L}^{+}$and $\gamma_{L}^{-}$for the reference liquids such as methylene iodide, $\alpha$-bromo naphthalene, ethylene glycol, glycerol and formamide, which was supplied by van Oss-Good by using arbitrary relation, $\gamma_{W}^{+}=\gamma_{W}^{-}$for water $[4,17]$, in order to apply Eq. (1) to the $\theta_{e}$ data. In general, three forms of Eq. (1) are simultaneously solved by using the $\theta_{e}$ data of three different liquids with two of them being polar and hydrogenbonding.

We calculated $\gamma_{S}^{-}, \gamma_{S}^{+}, \gamma_{S}^{\mathrm{AB}}$, and $\gamma_{S}^{\text {tot }}$ values of the polymers by using Eq. (1) according to van Oss-Good-Chaudhury method after determining the $\theta_{e}$ values of the methylene iodide $\left(\mathrm{MeI}_{2}\right)$, ethylene glycol (EG), and formamide (F) test liquids, which are given in Table 4. The calculated surface free energy results of all the samples are reported in Table 5 . We plotted the variation of atomic oxygen surface concentration for $90^{\circ}$ take-off angle and electron donor parameter, $\gamma_{S}^{-}$with the increase of the VA content in bulk (wt.\%) in Fig. 5 and very good agreement was obtained between $\gamma_{S}^{-}$ 


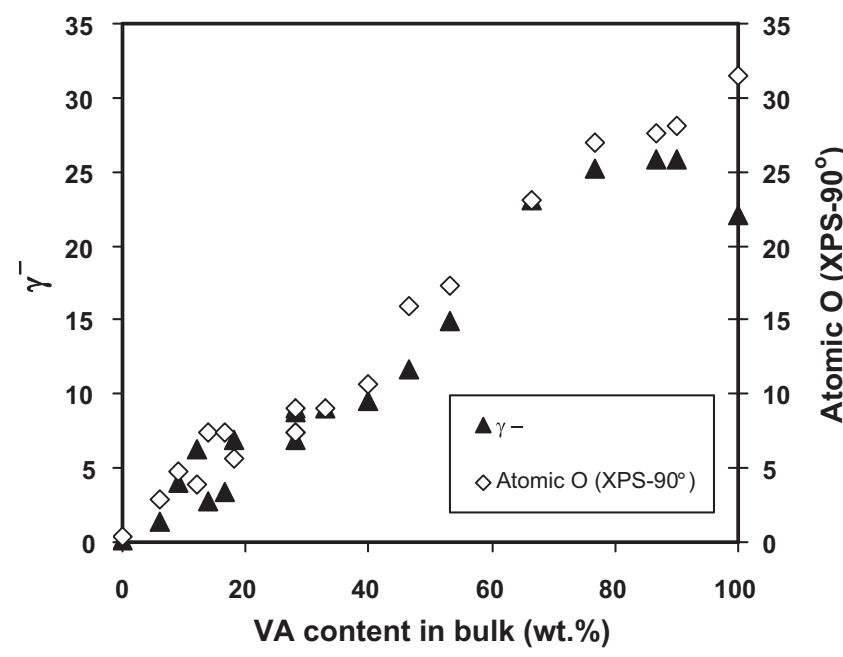

Fig. 5. Plot of the atomic oxygen surface concentration obtained by XPS measurements at $90^{\circ}$ take-off angle and electron donor parameter, $\gamma_{S}^{-}$with the increase of VA content in bulk (wt.\%).

and atomic oxygen concentration similar to another recent report showing the strength of the van Oss-Good-Chaudhury method [26]. The increase in VA content resulted in a small rise in the total surface free energy component, $\gamma_{S}^{\text {tot }}$ as seen in Table 5 however there was no direct relationship between $\gamma_{S}^{\text {tot }}$ and VA content especially for blends probably due to the introduction of surface roughness by phase-separation on these blend coatings.

\subsection{Applicability of Cassie-Baxter equation}

In 1944, Cassie-Baxter [25] derived an equation for twocomponent composite solid surfaces with varying degrees of heterogeneities and defined the equilibrium Cassie-Baxter contact angle, $\theta_{\mathrm{CB}}$.

$\cos \theta_{\mathrm{CB}}=f_{1} \cos \theta_{1}-f_{2} \cos \theta_{2}$

$f_{1}$ and $f_{2}$ are the liquid/solid contact area fractions of solid components 1 and 2 on the surface and $\theta_{1}$ and $\theta_{2}$ indicate the contact angles which are measured on flat 1 and 2 surfaces respectively. Eq. (2) indicates that the contact angle measured on a heterogeneous surface can be calculated if the area fractions of the polymer components are known. Cassie-Baxter equation was found to be useful

Table 5

Surface free energy results of polymer surfaces calculated by using van Oss-Good equation $\left(\mathrm{mJ} / \mathrm{m}^{2}\right)$.

\begin{tabular}{llllll}
\hline Polymer & $\gamma_{S}^{\mathrm{LW}}$ & $\gamma_{S}^{+}$ & $\gamma_{S}^{-}$ & $\gamma_{S}^{\mathrm{AB}}$ & $\gamma_{S}^{\text {tot }}$ \\
\hline HDPE & 32.6 & 0.0 & 0.2 & 0.0 & 32.6 \\
EVA-12/HDPE (50/50) & 35.9 & 0.0 & 1.4 & 0.0 & 35.9 \\
EVA-18/HDPE (50/50) & 36.5 & 0.0 & 4.0 & 0.0 & 36.5 \\
EVA 12 & 34.8 & 0.0 & 6.3 & 0.0 & 34.8 \\
EVA-28/HDPE (50/50) & 35.9 & 0.0 & 2.8 & 0.0 & 35.9 \\
EVA-33/HDPE (50/50) & 38.6 & 0.0 & 3.4 & 0.0 & 38.6 \\
EVA 18 & 36.5 & 0.0 & 6.9 & 0.0 & 36.5 \\
EVA 28-05 & 37.0 & 0.0 & 8.8 & 0.0 & 37.0 \\
EVA 28-40 & 38.1 & 0.0 & 6.9 & 0.0 & 38.1 \\
EVA 28-150 & 34.8 & 0.0 & 9.0 & 0.0 & 34.8 \\
EVA 33-400 & 38.1 & 0.0 & 9.0 & 0.0 & 38.1 \\
EVA 40 & 38.6 & 0.0 & 9.5 & 0.0 & 38.6 \\
PVAc/EVA-33 (20/80) & 35.9 & 0.0 & 11.6 & 0.0 & 35.9 \\
PVAc/EVA-33 (30/70) & 34.8 & 0.0 & 14.9 & 0.0 & 34.8 \\
PVAc/EVA-33 (50/50) & 39.1 & 0.0 & 23.1 & 0.0 & 39.1 \\
PVAc/EVA-33 (65/35) & 37.0 & 0.01 & 25.2 & 1.0 & 38.0 \\
PVAc/EVA-33 (80/20) & 37.0 & 0.0 & 25.8 & 0.0 & 37.0 \\
PVAc/EVA-33 (85/15) & 37.0 & 0.0 & 25.8 & 0.0 & 37.0 \\
PVAc & 39.1 & 0.2 & 22.1 & 4.2 & 43.3 \\
\hline
\end{tabular}

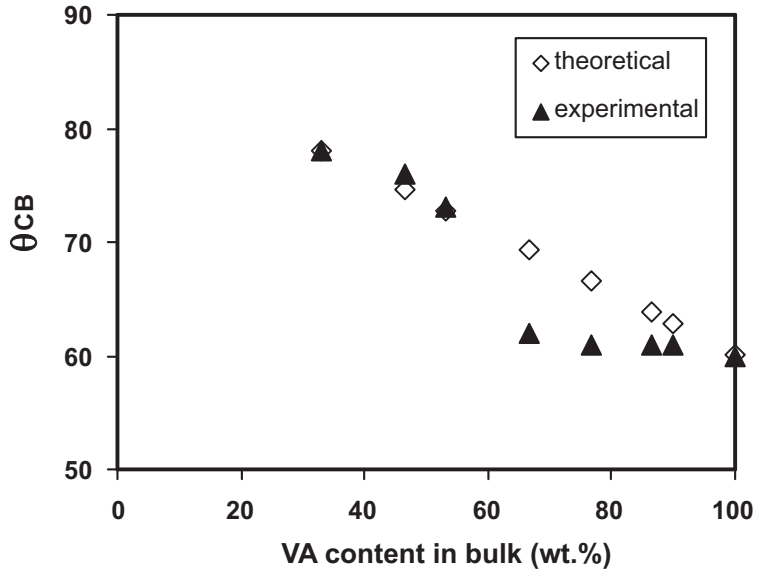

Fig. 6. Theoretical Cassie-Baxter and experimentally measured contact angles versus the VA content in bulk (wt.\%) by using weight fraction calculation.

in the analysis of chemically heterogeneous flat surfaces, and also air pocket containing rough surfaces although it cannot explain the corrugation of the three-phase contact line between the drop and solid [31].

We tested the applicability of the Cassie-Baxter equation to the chemically heterogeneous PVAc/EVA-33 blend surfaces: We assumed that the solid area fractions $f_{1}$ and $f_{2}$ are equal to the weight fractions on the surface and calculated them for PVAc homopolymer and EVA-33 copolymer separately. We measured water $\theta_{e}$ on flat PVAc and EVA-33 as $\theta_{1}$ and $\theta_{2}$. Then we solved Eq. (2) for the PVAc/EVA-33 blends and calculated the theoretical Cassie-Baxter contact angle, $\theta^{\mathrm{CB}}$. Fig. 6 shows the variation of the theoretical Cassie-Baxter and experimentally measured contact angles with the increase of VA content in bulk by using the weight fraction results. As seen in this figure, Cassie-Baxter theory gives good agreement with the experimental results below 55 wt.\% total VA content in bulk which can be attributed to the presence of the higher concentration of the more hydrophobic EVA regions on the surface. However, theoretical Cassie-Baxter contact angles and experimental ones did not fit with each other for the VA contents which were higher than $55 \mathrm{wt}$.\% probably due the increase in hydrophilicity arises from the VA group. In this region, $\theta_{e}$ results of the blends were very close to the results of PVAc homopolymer as given in Table 3 . This shows that the Cassie-Baxter equation gives better results for the cases where hydrophobic regions dominate on the surface.

\section{Conclusions}

Large area patterns having controlled protrusion sizes were obtained for PVAc/EVA-33 blends by applying an inexpensive dip coating method. A reasonably linear relation was found between the VA content on the surface (wt.\%) obtained from XPS analysis and the VA content in bulk especially for PVAc/EVA-33 blend surfaces. For pure EVA copolymer surfaces, PE segments are more enriched on the surface than that of the bulk similar to previous reports. However, we determined VA enrichment on the EVA/HDPE blend surfaces, which may be attributed to the high molecular weight of HDPE.

The increase in polar and hydrogen-bonding VA content on polymer surface resulted in a decrease $\theta_{e}$ values of water drop. The relation between surface free energy and XPS results was investigated and a good agreement was obtained between basic surface free energy component, $\gamma_{s}^{-}$, and atomic oxygen surface concentration with the increase of VA content. We also tested the applicability of the Cassie-Baxter theory and a good agreement was 
found with the experimental water $\theta_{e}$ results for surfaces having below 55 wt.\% total VA content. However, when VA contents were higher than $55 \mathrm{wt} . \%$, then there was a poor agreement with this theory and experimental results probably due to the increase in hydrophilic regions on the surface containing VA groups. In conclusion, Cassie-Baxter equation fits the experimental results better for the cases where hydrophobic regions dominate on the surface.

\section{References}

[1] D.R. Paul, S. Newman, Polymer Blends, Academic Press, New York, 1978.

[2] M.C. Michalski, J. Hardy, B.J.H. Saramago, J. Colloid Interface Sci. 208 (1998) 319-328.

[3] S. Chattopadyay, R.N. Ghosh, T.K. Chaki, A.K. Bhowmick, J. Adhes. Sci. Technol. 15 (2001) 303-320.

[4] H.Y. Erbil, Surface Chemistry of Solid and Liquid Interfaces, Blackwell Publishing, Oxford, UK, 2006.

[5] Z.I. Ali, J. Appl. Polym. Sci. 104 (2007) 2886-2895.

[6] E. Helfand, Z.R. Wasserman, Macromolecules 9 (1976) 879-888.

[7] S.K. Kumar, T.P. Russell, Macromolecules 24 (1991) 3816-3820.

[8] Y. Li, Y. Yang, F. Yu, L. Dong, J. Polym. Sci. Part B: Polym. Phys. 44 (2006) 9-21.

[9] M. Yin, Y. Yuan, C. Liu, J. Wang, Biomaterials 30 (2009) 2764-2773.

[10] I.O. Ucar, C.E. Cansoy, H.Y. Erbil, M.E. Pettitt, M.E. Callow, J.A. Callow, Biointerphases 5 (2010) 75-84.

[11] A.M. Henderson, IEEE Elec. Insul. Mag. 9 (1993) 30-38.
[12] H.Y. Erbil, Vinyl Acetate Emulsion Polymerization and Copolymerization with Acrylic Monomers, CRC Press, USA, 2000.

[13] T. Matsunaga, Y. Tamai, J. Appl. Polym. Sci. 22 (1978) 3525-3530.

[14] H.Y. Erbil, J. Appl. Polym. Sci. 33 (1987) 1397-1412.

[15] J.R. Dann, J. Colloid Interface Sci. 32 (1970) 302-320.

[16] S.J. Park, H.C. Kim, H.Y. Kim, J. Colloid Interface Sci. 255 (2002) 145-149.

[17] C.J. van Oss, M.K. Chaudhury, R.J. Good, Chem. Rev. 88 (1988) 927-941.

[18] K. Grundke, H.J. Jacobasch, F. Simon, S.T. Schneider, J. Adhes. Sci. Technol. 9 (1995) 327-350.

[19] T. Chihani, P. Bergmark, P. Flodin, J Adhes. Sci. Technol. 9 (1995) 843-857.

[20] A.A. Galuska, Surf. Interface Anal. 21 (1994) 703-710.

[21] R.L. McEvoy, S. Krause, P. Wu, Polymer 39 (1998) 5223-5239.

[22] C.M. Cepeda-Jimenez, R. Torregrosa-Macia, J.M. Martin-Martinez, J. Adhes. Sci. Technol. 17 (2003) 1145-1159.

[23] M.D. Landete-Ruiz, J.M. Martin-Martinez, Int. J. Adhes. Adhes. 25 (2005) 139-145.

[24] M.D. Doganci, C.E. Cansoy, I.O. Ucar, H.Y. Erbil, E. Mielczarski, J.A. Mielczarski, J. Appl. Poly. Sci., in preparation.

[25] A.B.D. Cassie, S. Baxter, Trans. Faraday. Soc. 40 (1944) 546-551.

[26] H.Y. Erbil, B. Yaşar, S. Suzer, B.M. Baysal, Langmuir 13 (1997) 5484-5493.

[27] G. Beamson, D. Briggs, High Resolution XPS of Organic Polymers: The Scienta ESCA300 Database, Wiley, Chichester, 1992.

[28] B. Na, Q. Zhang, Q. Fu, G. Zhang, K. Shen, Polymer 43 (2002) 7367-7376.

[29] C. Devallencourt, S. Marais, J.M. Saiter, M. Labbe, M. Métayer, Polym. Test. 21 (2002) 253-262.

[30] F.J. du Toit, R.D. Sanderson, W.J. Engelbrecht, J.B. Wagener, J. Fluorine Chem. 74 (1995) 43-48.

[31] H.Y. Erbil, C.E. Cansoy, Langmuir 25 (2009) 14135-14145

[32] W.L. Lee, M. Hong, E. Wijdada, S.C.J. Loo, Macromol. Rapid Commun. 31 (2010) 1193-1200. 